\title{
Theoretical Cross-Section Calculation of In-111, Tc-99m, Co-57 Radioisotopes Used for Kidney Imaging
}

\author{
F. KilinÇ ${ }^{a}$, N. KARPUZ ${ }^{b}$ AND B. ÇETIN ${ }^{a, *}$ \\ ${ }^{a}$ Amasya University, Sciences \& Arts Faculty, Amasya, Turkey \\ ${ }^{b}$ Amasya University, Sabuncuoğlu Şerefeddin Health Services Vocational School, Amasya, Turkey \\ Many radioisotopes are used in nuclear medicine diagnostics and therapy. Co- 57 , In-111 and Tc-99m isotopes \\ are widely used in nuclear medicine and are successfully implemented in renal imaging. In this work, the cross \\ section calculation of the $(\mathrm{p}, 2 \mathrm{n})$ reaction, which is necessary for production of the nuclei of Co- 57 , In- 111 , Tc-99m, \\ were calculated using TALYS 1.6 nuclear reaction code. The calculated cross sections were compared with the \\ experimental data from the EXFOR.
}

DOI: 10.12693/APhysPolA.130.311

PACS/topics: 13.85.Lg, 13.87.Ce

\section{Introduction}

Radioisotopes are needed for the detection of functional disorders of organs in medical physics and diagnosis and in treatment of many diseases. Nuclear reactions are used for the production of radioisotopes. Possibility to estimate the probability of the realization of a nuclear reaction will very beneficial, from the financial point of view. It will also eliminate the risk of physical exposure to radiation. It is important to be able to estimate the effective energy range of a reaction. Reaction cross section gives information about the probability of the realization of a nuclear reaction.

Tc- $99 \mathrm{~m}$ is the most used radionuclide in the scintigraphic imaging applied in diagnostics. It has a half-life of 6 hours. Produced in radioisotope generators, it does not emit particle radiation. it emits only gamma rays with single energy of $140 \mathrm{keV}$. Such physical properties are ideal for the gamma imaging technique. The properties of ${ }^{99 m} \mathrm{Tc}$ ensure good quality of scintigraphic images and a low radiation dose to which the patient is exposed [1].

In-111 is used for monitoring of organs like liver and kidneys, in the tumor imaging and in the treatment of leukemia. It has a half-life of 2.81 days. It emits gamma photons with energies of $172 \mathrm{keV}(91 \%)$ and $247 \mathrm{keV}$ (94\%) [2].

Co-57 is used for monitoring of kidneys, bladder, liver and bone marrow. It is used for radioisotope dose calibrators in nuclear medicine and as a gamma-source in the measurement systems and gamma cameras. It is used also in the calibration of quality control detectors [3]. It emits photon energies of $122 \mathrm{keV}(86 \%)$ and $136 \mathrm{keV}$ $(10 \%)$ [2]. It has a half-life of 270 days.

Ideal radioisotope should emit in the energy range of 100-200 keV and have a suitable half-life. It should be easily obtainable and should have an appropriate price.

\footnotetext{
*corresponding author; e-mail: betulcetin3205@hotmail.com
}

This theoretical study of production of radioisotopes, used in kidney imaging, is of informative nature.

Different studies have been using TALYS code for calculation of nuclear reaction cross sections. Cross sections of the $(\mathrm{n}, \mathrm{f})$ reaction for ${ }^{235} \mathrm{U}$ have been calculated in [3]. In the fission reaction of the ${ }^{235} \mathrm{U}$ nucleus the ${ }^{137} \mathrm{Cs}$ isotope is produced, which is used in radiation therapy, because of its suitable half-live. ${ }^{125} \mathrm{Te}(\mathrm{p}, \mathrm{xn})$ reaction, during which the iodine isotope can be produced, was simulated in the 5.5-100.5 MeV energy range using TALYS code in [4]. The calculated ${ }^{125} \mathrm{Te}(\mathrm{p}, \mathrm{xn})$ cross sections have been compared with results obtained using ALICE/ASH code.

Aside from the medical studies, TALYS code was also used in photonuclear applications. Zirconium is a very strong metal and it is the best construction material for nuclear reactor parts, like cladding of fuel elements, due to its low neutron capture cross-section. The zirconium is also a potential target for the production of medical isotopes. For this reason, the cross sections of $(\gamma, \mathrm{n})$ reaction in ${ }^{\text {nat }} \mathrm{Zr},{ }^{90} \mathrm{Zr},{ }^{91} \mathrm{Zr},{ }^{92} \mathrm{Zr},{ }^{94} \mathrm{Zr}$ and ${ }^{96} \mathrm{Zr}$ targets have been calculated using the TALYS code in [5].

\section{Materials and methods}

${ }^{99 m} \mathrm{Tc},{ }^{111} \mathrm{In}$ and ${ }^{57} \mathrm{Co}$ are the radioisotopes used in nuclear medicine. ${ }^{100} \mathrm{Mo},{ }^{58} \mathrm{Fe}$ and ${ }^{112} \mathrm{Cd}$ isotopes are also used in medicine. ${ }^{99 m} \mathrm{Tc},{ }^{111} \mathrm{In}$ and ${ }^{57} \mathrm{Co}$ are used as target materials for the production of radioisotopes. These radioisotopes are used in kidney imaging.

In this study, the cross sections of ${ }^{100} \mathrm{Mo}(\mathrm{p}, 2 \mathrm{n}){ }^{99 m} \mathrm{Tc}$, ${ }^{58} \mathrm{Fe}(\mathrm{p}, 2 \mathrm{n}){ }^{57} \mathrm{Co},{ }^{112} \mathrm{Cd}(\mathrm{p}, 2 \mathrm{n}){ }^{111} \mathrm{In}$ reactions were calculated. The calculations were carrie out using TALYS 1.6 program for Monte Carlo simulation of nuclear reactions. TALYS $1.6[6]$ program examines the interaction with the nucleus, with a mass of 12 or heavier, of incoming particles like protons, neutrons, deuterons, tritons, gamma, alpha and $3 \mathrm{He}$ particles in the energy range of $1 \mathrm{keV}$ $1 \mathrm{GeV}$. It is written in FORTRAN programming language and runs on Linux operation system. 


\section{Results and discussions}

The calculated ${ }^{100} \mathrm{Mo}(\mathrm{p}, 2 \mathrm{n}){ }^{99 m} \mathrm{Tc},{ }^{58} \mathrm{Fe}(\mathrm{p}, 2 \mathrm{n}){ }^{57} \mathrm{Co}$, ${ }^{112} \mathrm{Cd}(\mathrm{p}, 2 \mathrm{n}){ }^{111} \mathrm{In}$ production reaction cross sections are shown in Figs. 1, 2 and 3.

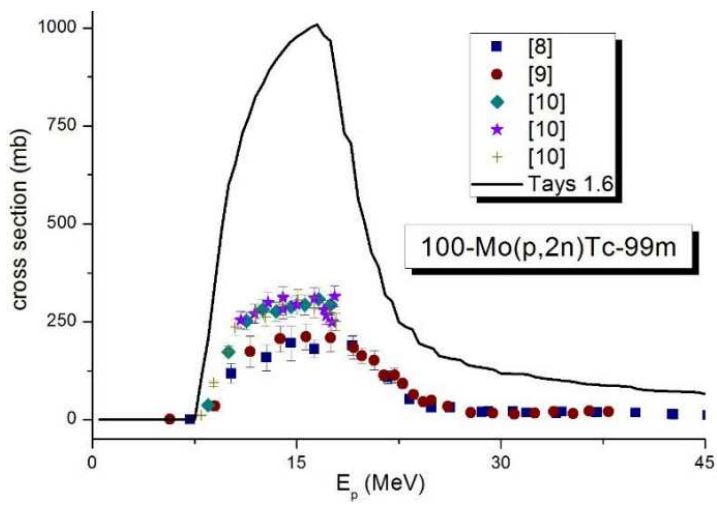

Fig. 1. The calculated cross sections of ${ }^{100} \mathrm{Mo}(\mathrm{p}, 2 \mathrm{n})$ ${ }^{99 m} \mathrm{Tc}$ reaction and comparison with experimental results.

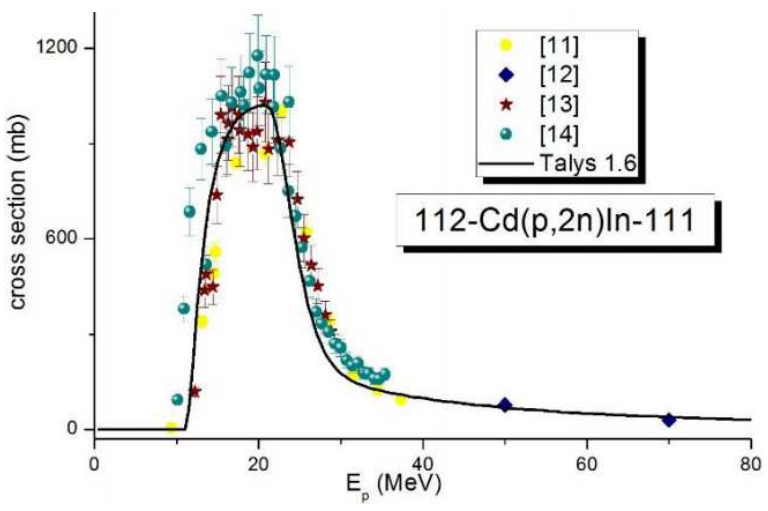

Fig. 2. The calculated cross sections of ${ }^{112} \mathrm{Cd}(\mathrm{p}, 2 \mathrm{n})$ ${ }^{111}$ In reaction and comparison with experimental results.

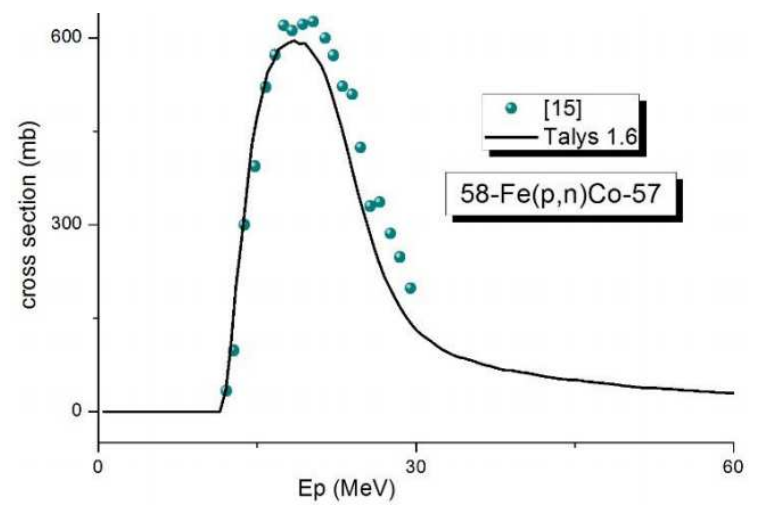

Fig. 3. The calculated cross sections of ${ }^{58} \mathrm{Fe}$ $(\mathrm{p}, 2 \mathrm{n}){ }^{57} \mathrm{Co}$ reaction and comparison with experimental results.
The obtained results are compared with the experimental data existing in the EXFOR [7] databases.

\section{Conclusions}

In this work production cross sections for the reactions of ${ }^{100} \mathrm{Mo}(\mathrm{p}, 2 \mathrm{n}){ }^{99 m} \mathrm{Tc},{ }^{58} \mathrm{Fe}(\mathrm{p}, 2 \mathrm{n}){ }^{57} \mathrm{Co}$ and ${ }^{112} \mathrm{Cd}$ $(\mathrm{p}, 2 \mathrm{n})^{111} \mathrm{In}$ were calculated in the energy range between 1 and $100 \mathrm{MeV}$. Our results are in fair agreement with experimental data available in literature. The maximum cross section values are $1008.45 \mathrm{mb}$ at $16.5 \mathrm{MeV}$ for ${ }^{99 m}$ Tc production, $1021.14 \mathrm{mb}$ at $20.5 \mathrm{MeV}$ for ${ }^{111} \mathrm{In}$ and $591.477 \mathrm{mb}$ at $19.5 \mathrm{MeV}$ for ${ }^{57} \mathrm{Co}$ production. The most appropriate production range for Tc-99m using ${ }^{100} \mathrm{Mo}$ $(\mathrm{p}, 2 \mathrm{n})^{99 m} \mathrm{Tc}$ nuclear reaction is $13-18 \mathrm{MeV}$. The most appropriate production range for ${ }^{111} \mathrm{In}$ using ${ }^{112} \mathrm{Cd}(\mathrm{p}, 2 \mathrm{n})$ ${ }^{111} \mathrm{In}$ nuclear reaction is $16-23 \mathrm{MeV}$. The most appropriate production range for ${ }^{57} \mathrm{Co}$ using ${ }^{58} \mathrm{Fe}(\mathrm{p}, 2 \mathrm{n}){ }^{57} \mathrm{Co}$ nuclear reaction is $16-20 \mathrm{MeV}$.

Reaction cross sections for production of ${ }^{99 m} \mathrm{Tc},{ }^{111} \mathrm{In}$ and ${ }^{57} \mathrm{Co}$ medicine radioisotopes were calculated theoretically. The calculated results were compared with the results of experimental data from literature. It is seen that the theoretical results calculated using the TALYS 1.6 program are compatible with the experimental data taken from literature.

\section{References}

[1] İ.E. Atak, M.Sc. Thesis, Hacettepe Üniversitesi Sağlık Bilimleri Enstitüsü, 2004.

[2] F. Savaş, M.Sc. Thesis, Çukurova Üniversitesi Fizik Anabilim Dalı, 2013.

[3] N. Karpuz, M.C. Boz, B. Mavi, F. Öner, İ. Akkurt, Acta Phys. Pol. A 128, B-363 (2015).

[4] N. Karpuz, İ. Akkurt, B. Mavi, Ann. Nucl. Energy 60, 341 (2013).

[5] İ. Akkurt, N. Karpuz, B. Mavi, N. Demir, Ann. Nucl. Energy 65, 181 (2014).

[6] A. Koning, S. Hilaire, S. Goriely, TALYS-1.6 A Nuclear Reaction Program, User Manual, NRG, The Netherlands, 2013.

[7] EXFOR/CSISRS, Experimental Nuclear Reaction Data File, Brookhaven National Laboratory, National Nuclear Data Center, 2009. 